\title{
Phase II SBIR Final Scientific/Technical Report
}

\author{
DOE award number: DE-FG02-06ER8448
}

Recipient: Specialty Materials, Inc., Lowell, Massachusetts

Project Title: Plasma Synthesized Doped Boron Nanopowder for $\mathrm{MgB}_{2}$ Superconductors

Principal Investigator: James V. Marzik, Ph.D., Chief Scientist, Specialty Materials, Inc.

\section{Key Personnel:}

- Paul Canfield, Ph.D., Professor of Physics and Astronomy, lowa State University, and Physicist, Ames Laboratory, Ames, IA

- Douglas Finnemore, Ph.D., Professor Emeritus, lowa State University, and Physicist, Ames Laboratory, Ames, IA

- Michael Tomsic, President, Hyper Tech Research, Inc. Columbus, OH

- Sanjay Sampath, Professor of Materials Science, State University of New York at Stony Brook, Stony Brook, NY

\section{Executive Summary:}

Under this program, a process to synthesize nano-sized doped boron powder by a plasma synthesis process was developed and scaled up from 20 gram batches at program start to over 200 grams by program end. Over 75 batches of boron nanopowder were made by RF plasma synthesis. Particle sizes were typically in the $20-200 \mathrm{~nm}$ range. The powder was synthesized by the reductive pyrolysis of $\mathrm{BCl}_{3}$ in hydrogen in an $\mathrm{RF}$ plasma. A wide range of process parameters were investigated including plasma power, torch geometry, gas flow rates, and process pressure. The powder-in-tube technique was used to make monofilament and multifilament superconducting wires. $\mathrm{MgB}_{2}$ wire made with Specialty Materials' plasma synthesized boron nanopowder exhibited superconducting properties that significantly exceeded the program goals. Superconducting critical currents, $\mathrm{J}_{c}$, in excess of $10^{5} \mathrm{~A}$ $\mathrm{cm}^{-2}$ at magnetic fields of 8 tesla were reproducibly achieved. The upper critical magnetic field in wires fabricated with program boron powder were $\mathrm{H}_{\mathrm{c} 2}(0)=37$ tesla, demonstrating the potential of these materials for high field magnet applications. $\mathrm{T}_{\mathrm{c}}$ in carbon-doped $\mathrm{MgB}_{2}$ powder showed a systematic decrease with increasing carbon precursor gas flows, indicating the plasma synthesis process can give precise control over dopant concentrations. Synthesis rates increased by a factor of $400 \%$ over the course of the program, demonstrating the scalability of the powder synthesis process.

The plasma synthesis equipment at Specialty Materials has successfully and reproducibly made high quality boron nanopowder for $\mathrm{MgB}_{2}$ superconductors. Research and development from this program enabled Specialty Materials to successfully scale up the powder synthesis process by a factor of ten and to double the size of its powder pilot plant. Thus far the program has been a technical success. It is anticipated that continued systematic development of plasma processing parameters, dopant chemistry and concentration, wire processing technology, and collection technology will lead to the 
commercialization of boron nanopowder as a precursor for $\mathrm{MgB}_{2}$ superconductors. Potential commercial applications include magnets for magnetic resonance imaging (MRI), fault current limiters, wind turbine generators.

\section{Comparison of Accomplishments with Goal/Objectives:}

At program start, the critical current densities, $J_{c}$, and upper critical magnetic fields, $\mathrm{H}_{\mathrm{c} 2}$, of undoped $\mathrm{MgB}_{2}$ were not high enough to be of interest for commercial development of superconducting wire. No existing or proposed wire processing approach was available to overcome this problem. Doped $\mathrm{MgB}_{2}$ is needed to produce a viable end product. It was hypothesized that the dopant will produce precipitates which enhance magnetic flux pinning for higher critical current densities, $J_{c}$, and perturb the crystal structure resulting in a shorter electron mean free path for greater upper critical magnetic fields, $\mathrm{H}_{\mathrm{c} 2}$. The objective of this effort was the production of a fine-scale doped boron powder used as the starting material for conversion to $\mathrm{MgB}_{2}$. The doped boron was synthesized in a plasma from boron trichloride and suitable precursors to introduce dopants. Carbon and titanium were investigated as dopants and optimum compositions will be defined. The effect of powder particle size, purity, dopant concentration, and chemical homogeneity on the superconducting properties of $\mathrm{MgB}_{2}$ will be systemmatically investigated. The improvement and optimization of doped boron nanopowder as a feedstock for the powder-in-tube wire manufacturing process will be an on-going objective of this program.

The plasma synthesis technique for producing doped boron provides to unique technological advantages:

- The small particle sizes ( $<100 \mathrm{~nm}$ ) of the doped boron reactants result in $\mathrm{MgB}_{2}$ wires with better superconducting properties at lower processing temperatures.

- The plasma synthesis technique results in very fine scale and uniform dispersion of dopants, leading to better, more reproducible superconducting properties.

\section{Results Compared to the Proposed Phase II Work Plan}

\section{Task 1: Plasma Boron Powder Synthesis Development Conditions}

- Task Milestones

- Deliver at least twenty (20) lots of boron powder ( 20-100g batches) with at least ten (10) different combinations of dopant conditions (dopant chemicals and concentrations) for use in Task 3 
- Dopants will include but not be limited to carbon, titanium, silicon carbide and combinations of two or more of these

Task 2: Plasma parametric study

- Task Milestones

- Deliver at least ten (20) lots of boron powder ( 20-100g batches) with at least ten (10) different combinations of plasma process parameters for use in Task 3

- Plasma process parameters will include but not be limited to gun design, power levels, gas flows, pressure and gas residence time combinations of two or more of these

\section{Task 1 and 2 Results:}

Table 1 gives a summary of $75+$ batches of boron powder made using the plasma synthesis equipment at Specialty Materials, Inc. This quantity greatly exceeds the number of proposed number of batches for this Phase 2 program. Both undoped and carbon doped powder were synthesized. In addition to the powder batches listed below, five batches of titanium doped boron nanopowder was synthesized and Stony Brook University with a range of Ti dopant concentration. Batch sizes ranged from less than 10 grams to 200 grams. Typical powder batch sizes at Specialty Materials by program end were $>200$ grams.

Doped and undoped boron powder batches were synthesized at varying process pressures and reactant gas flows. The temperature was varied by adjusting the plasma power. Three different torch designs were investigated, which produced RF plasmas at three different frequencies (2.1, 3.0, and 3.6 $\mathrm{MHz}$ ). Portions of the powder batches were delivered to Ames Laboratory to evaluate the superconducting properties of $\mathrm{MgB}_{2}$ made from these powders, and to Hyper Tech Research so that powder-in-tube $\mathrm{MgB}_{2}$ wires could be fabricated. 
Table 1. Summary of boron powder plasma synthesis parameters made during this Phase 2 program. Over 75 powder experiments were conducted investigating several process parameters including plasma power, gas flows, system pressure, and dopant concentration. This far exceeded the proposed goals of the program.

\begin{tabular}{|c|c|c|c|c|c|c|c|c|c|c|c|}
\hline \multicolumn{12}{|c|}{ Boron powder RF plasma synthesis runs } \\
\hline \multirow{2}{*}{ Sample \# } & \multirow[b]{2}{*}{ Voltage (kV) } & Plasma powe & & System & ssure ( & & Gas & ows ( $(1 / \mathrm{mi}$ & & & \\
\hline & & Current (A) & Power (kW) & Start & End & $\mathrm{BCl}_{3}$ & $\mathrm{H}_{2 \text { bot }}$ & $\mathrm{H}_{2 \mathrm{rad} / \mathrm{sw}}$ & $\mathrm{Ar}_{\mathrm{rad} / \mathrm{sw}}$ & $\mathrm{Ar}_{\mathrm{ax}}$ & Dopant \\
\hline SMI-010308 & 5.5 & 3.2 & 17.6 & 197 & 208 & $0.75-1.0$ & 15 & 0 & 35 & 5 & -- \\
\hline SMI-010908 & 5.3 & 3.25 & 17.2 & 180 & 205 & $0.75-0.90$ & 15 & 0 & 35 & 5 & - \\
\hline SMI-011108 & 5.4 & 3.3 & 17.8 & 158 & 200 & 1.0 & 20 & 0 & 35 & 5 & -- \\
\hline SMI-011508 & 6.9 & 3.75 & 25.9 & 184 & 223 & 2.0 & 20 & 0 & 35 & 5 & -- \\
\hline SMI-011808 & 6.2 & 3.55 & 22.0 & 185 & 226 & 2.0 & 20 & 0 & 35 & 5 & -- \\
\hline SMI-012308 & 6.3 & 3.55 & 22.4 & 208 & 262 & 2.0 & 20 & 0 & 35 & 5 & -- \\
\hline SMI-012808 & 6.3 & 3.55 & 22.4 & 189 & 352 & 2.6 & 30 & 0 & 35 & 5 & - \\
\hline SMI-020108 & 6.6 & 3.65 & 24.1 & 205 & 407 & 3.45 & 30 & 0 & 35 & 5 & -- \\
\hline SMI-020508 & 7.2 & 3.95 & 28.4 & 223 & 325 & 3.30 & 35 & 0 & 35 & 5 & -- \\
\hline SMI-021308 & 6.3 & 3.2 & 20.2 & 197 & 280 & 3.38 & 15 & 0 & 35 & 5 & - \\
\hline SMI-022108 & 6.8 & 3.6 & 24.5 & 232 & 328 & 3.30 & 20 & 0 & 35 & 5 & -- \\
\hline SMI-030308 & 8.3 & 3 & 24.9 & 219 & 260 & 3.30 & 15 & 5 & 35 & 5 & -- \\
\hline SMI-031008 & 8.2 & 2.9 & 23.8 & 213 & 218 & $1.0-3.23$ & 15 & 5 & 35 & 5 & -- \\
\hline SMI-031808 & 6.2 & 3.6 & 22.3 & 209 & 200 & $0.8-3.7$ & 20 & 0 & 35 & 5 & - \\
\hline SMI-032708 & 6.8 & 3.5 & 23.8 & 215 & 286 & 3.70 & 20 & 0 & 35 & 5 & -- \\
\hline SMI-040208 & 6.7 & 3.5 & 23.5 & 210 & 278 & 3.30 & 27 & 0 & 35 & 5 & 0.066 \\
\hline SMI-040708 & 6.7 & 3.5 & 23.5 & 208 & 272 & 3.30 & 20 & 0 & 35 & 5 & 0.050 \\
\hline SMI-041108 & 6.2 & 3.65 & 22.6 & 214 & 251 & 3.30 & 20 & 0 & 35 & 5 & 0.033 \\
\hline SMI-041608 & 6.2 & 3.6 & 22.3 & 205 & 245 & 3.30 & 20 & 0 & 35 & 5 & 0.083 \\
\hline SMI-042308 & 6.0 & 3.35 & 20.1 & 200 & 240 & 3.30 & 20 & 0 & 35 & 5 & 0.066 \\
\hline SMI-043008 & 6.6 & 3.05 & 20.1 & 200 & 227 & 3.30 & 20 & 1.4 & 35 & 5 & 0.066 \\
\hline SMI-050808 & 5.6 & 3.05 & 17.1 & 210 & 245 & 3.30 & 20 & 0 & 35 & 5 & 0.066 \\
\hline SMI-051608 & 5.7 & 2.95 & 16.7 & 210 & 260 & 3.30 & 20 & 0 & 35 & 5 & -- \\
\hline SMI-052108 & 5.8 & 2.95 & 17.1 & 210 & 244 & 3.30 & 20 & 0 & 35 & 5 & 0.066 \\
\hline SMI-052708 & 5.7 & 2.9 & 16.5 & 210 & 270 & 3.30 & 20 & 0 & 35 & 5 & -- \\
\hline SMI-052908 & 5.7 & 2.95 & 16.7 & 210 & 268 & 3.30 & 20 & 0 & 35 & 5 & -- \\
\hline SMI-060208 & 5.6 & 3 & 16.8 & 210 & 264 & 3.30 & 20 & 0 & 35 & 5 & 0.066 \\
\hline SMI-060408 & 5.8 & 2.9 & 16.8 & 210 & 270 & 3.30 & 20 & 0 & 35 & 5 & 0.066 \\
\hline SMI-061008 & 5.8 & 2.85 & 16.5 & 216 & 270 & 3.30 & 20 & 0 & 35 & 5 & 0.066 \\
\hline SMI-061608 & 5.6 & 2.8 & 15.7 & 206 & 268 & 3.30 & 20 & 0 & 35 & 5 & 0.066 \\
\hline SMI-062608 & 5.9 & 2.85 & 16.8 & 212 & 270 & 3.30 & 20 & 0 & 35 & 5 & 0.066 \\
\hline SMI-063008 & 5.9 & 2.85 & 16.8 & 208 & 265 & 3.30 & 20 & 0 & 35 & 5 & 0.066 \\
\hline SMI-070908 & 5.8 & 2.9 & 16.8 & 210 & 270 & 3.30 & 20 & 0 & 35 & 5 & 0.066 \\
\hline SMI-071408 & 5.8 & 2.9 & 16.8 & 210 & 275 & 3.30 & 20 & 0 & 35 & 5 & 0.066 \\
\hline SMI-072108 & 5.8 & 2.9 & 16.7 & 209 & 214 & 3.30 & 20 & 0 & 35 & 5 & 0.066 \\
\hline SMI-072408 & 5.8 & 2.95 & 17.1 & 215 & 275 & 3.30 & 20 & 0 & 35 & 5 & 0.066 \\
\hline SMI-073008 & 5.8 & 2.9 & 16.8 & 216 & 270 & 3.30 & 20 & 0 & 35 & 5 & 0.066 \\
\hline SMI-080808 & 5.8 & 2.9 & 16.8 & 210 & 270 & 3.30 & 20 & 0 & 35 & 5 & 0.066 \\
\hline SMI-082508 & 5.7 & 2.95 & 16.8 & 206 & 274 & 3.30 & 20 & 0 & 35 & 5 & 0.066 \\
\hline SMI-090208A & 5.7 & 2.95 & 16.8 & 210 & 280 & 3.30 & 20 & 0 & 35 & 5 & 0.100 \\
\hline SMI-090208B & 5.7 & 2.95 & 16.8 & 206 & 270 & 3.30 & 20 & 0 & 35 & 5 & 0.120 \\
\hline SMI-090408 & 5.7 & 2.95 & 16.8 & 210 & 270 & 3.30 & 20 & 0 & 35 & 5 & 0.066 \\
\hline SMI-091508 & 5.6 & 3.65 & 20.4 & 400 & 400 & 3.50 & 20 & 0 & 40 & 0 & 0.080 \\
\hline SMI-091908 & 5.5 & 3.1 & 16.9 & 220 & 220 & 3.30 & 20 & 0 & 37 & 5 & 0.066 \\
\hline SMI-092308 & 5.6 & 3.1 & 16.9 & 220 & 220 & 3.30 & 20 & 0 & 37 & 5 & 0.066 \\
\hline SMI-092908 & 5.5 & 3.1 & 16.8 & 220 & 220 & 3.30 & 20 & 0 & 37 & 5 & 0.000 \\
\hline SMI-100208 & 5.7 & 3.6 & 20.2 & 400 & 400 & 3.50 & 20 & 0 & 40 & 0 & 0.075 \\
\hline SMI-102008 & 5.2 & 3.1 & 15.9 & 400 & 400 & 3.50 & 20 & 0 & 40 & 0 & 0.075 \\
\hline SMI-102308 & 5.7 & 3.5 & 20.0 & 400 & 400 & 3.50 & 20 & 0 & 40 & 0 & 0.000 \\
\hline SMI-110308 & 5.1 & 3.2 & 16.2 & 400 & 400 & 3.50 & 20 & 0 & 40 & 0 & 0.075 \\
\hline SMI-111108 & 5.1 & 3.3 & 16.8 & 220 & 220 & 3.30 & 20 & 0 & 37 & 5 & 0.066 \\
\hline SMI-111908 & 5.1 & 3.3 & 16.8 & 220 & 220 & 3.30 & 20 & 0 & 37 & 5 & 0.066 \\
\hline SMI-112508 & 5.6 & 3.5 & 19.6 & 400 & 400 & 3.40 & 20 & 0 & 40 & 0 & 0.034 \\
\hline SMI-120808 & 5.6 & 3.5 & 19.6 & 400 & 400 & 3.50 & 20 & 0 & 40 & 0 & 0.000 \\
\hline SMI-122208 & 5.7 & 3.6 & 20.2 & 400 & 400 & 3.50 & 20 & 0 & 40 & 0 & 0.000 \\
\hline SMI-123008 & 5.7 & 3.5 & 20.0 & 400 & 400 & 3.45 & 20 & 0 & 40 & 0 & 0.069 \\
\hline SMI-011409 & 5.3 & 3.8 & 20.1 & 400 & 400 & 3.50 & 20 & 0 & 40 & 0 & 0.000 \\
\hline SMI-012209 & 5.3 & 3.8 & 20.1 & 400 & 400 & 3.50 & 20 & 0 & 40 & 0 & 0.000 \\
\hline SMI-020309 & 5.3 & 3.8 & 20.1 & 400 & 400 & 3.50 & 20 & 0 & 40 & 0 & 0.035 \\
\hline SMI-021009 & 6.2 & 3.0 & 18.3 & 400 & 400 & 3.50 & 20 & 0.8 & 40 & 0 & 0.000 \\
\hline SMI-021909 & 5.9 & 2.7 & 15.9 & 400 & 400 & 3.50 & 20 & 0.8 & 40 & 0 & 0.000 \\
\hline SMI-031209 & 5.9 & 2.7 & 15.9 & 400 & 400 & 3.50 & 20 & 0.8 & 40 & 0 & 0.070 \\
\hline SMI-041409 & 5.9 & 2.8 & 16.5 & 400 & 400 & 3.5 & 20 & 0.8 & 40 & 0 & 0.000 \\
\hline SMI-052009 & 6.0 & 3.0 & 18.0 & 400 & 400 & 3.5 & 20 & 0.8 & 40 & 0 & 0.070 \\
\hline SMI-052809 & 6.2 & 3.2 & 19.8 & 400 & 400 & 3.5 & 20 & 0.8 & 40 & 0 & 0.070 \\
\hline SMI-060309 & 5.7 & 3.5 & 20.0 & 400 & 400 & 3.5 & 20 & 0 & 40 & 0 & 0.070 \\
\hline SMI-060909 & 6.0 & 3.0 & 18.0 & 400 & 400 & 3.5 & 20 & 0.8 & 40 & 0 & 0.140 \\
\hline SMI-070909 & 5.8 & 3.5 & 20.0 & 400 & 400 & 3.5 & 20 & 0 & 40 & 0 & 0.000 \\
\hline SMI-081909 & 6.1 & 3.3 & 19.8 & 400 & 400 & 3.5 & 20 & 0.8 & 40 & 0 & 0.070 \\
\hline SMI-082609 & 5.9 & 3.1 & 18.0 & 400 & 400 & 3.5 & 20 & 0.8 & 40 & 0 & 0.105 \\
\hline SMI-090109 & 6.1 & 3.0 & 18.0 & 400 & 400 & 5.25 & 30 & 1.2 & 60 & 0 & 0.000 \\
\hline SMI-090909 & 6.1 & 3.0 & 18.0 & 400 & 400 & 5.25 & 30 & 1.2 & 60 & 0 & 0.105 \\
\hline SMI-092209 & 6.0 & 3.0 & 18.0 & 400 & 400 & 5.25 & 25 & 1 & 50 & 0 & 0.105 \\
\hline SMI-010710 & 5.9 & 3.1 & 18.0 & 400 & 400 & 3.5 & 20 & 0.8 & 40 & 0 & 0.070 \\
\hline SMI-011210 & 5.9 & 3.1 & 18.0 & 400 & 400 & 3.5 & 20 & 0.8 & 40 & 0 & 0.070 \\
\hline SMI-012810 & 6.0 & 3.0 & 18.0 & 400 & 400 & 3.5 & 20 & 0.8 & 40 & 0 & 0.070 \\
\hline SMI-020210A & 6.0 & 3.0 & 18.0 & 400 & 400 & 3.5 & 20 & 0.8 & 40 & 0 & 0.122 \\
\hline SMI-020210B & 6.0 & 3.0 & 18.0 & 400 & 400 & 3.5 & 20 & 0.8 & 40 & 0 & 0.175 \\
\hline
\end{tabular}




\section{SMI's pilot plasma synthesis system}

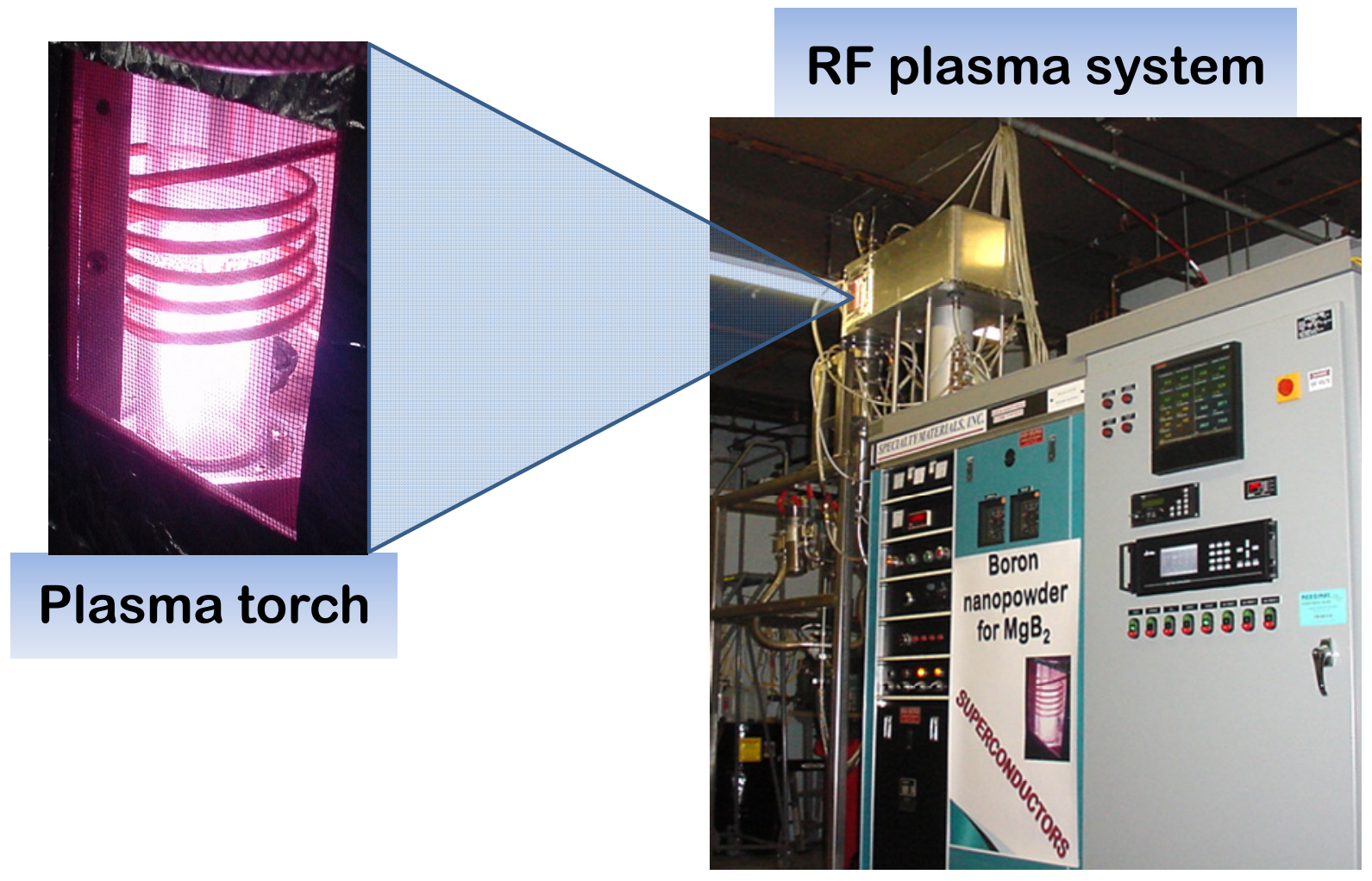

Figure 1. Specialty Materials' RF plasma system is shown during boron nanopowder synthesis. The torch is shielded by an aluminum box and copper screening. At the left is a close-up of the $\mathrm{RF}$ plasma torch. The pink color is typical of $\mathrm{Ar} / \mathrm{H}_{2}$ plasmas.

\section{Task 3: Characterization of boron nanopowder}

- Characterization of powder particle size

- The particle size and distribution will be characterized by scanning electron microscopy (SEM). Goals are undoped boron purity of $99 \%$, and particles sizes in the range of $10-100 \mathrm{~nm}$.

- Powder purity

- Purity of the doped boron nanopowders will be analyzed using a scanning electron microscope equipped with a light element energy dispersive x-ray spectrometer (SEM/EDS) and other analytical techniques such as glow discharge mass spectroscopy (GDMS).

- Dopant concentration and homogeneity 
- Concentration and distribution of dopants will be analyzed using a scanning electron microscope equipped with a light element energy dispersive x-ray spectrometer (SEM/EDS) and other analytical techniques such as glow discharge mass spectroscopy (GDMS).

- Powder crystallinity and crystallite size

- X-ray diffraction will be used to measure the crystallinity of the boron nanopowder. It is anticipated that the powder will be amorphous, but this will be monitored as a function of plasma processing conditions. Crystallite size will be evaluated using $x$-ray line broadening methods.

- Task Milestones:

- Develop process-property-performance diagrams for all variations of doped powder synthesized in this program

- Use powder properties to feedback into and improve process parameters

\section{Task 3 Results: Plasma Synthesized Boron Nano-sized Powder: The Effect of Processing Conditions on the Crystallographic and Microstructural Properties}

Boron nano-sized powders (doped and undoped) were synthesized by the reaction of boron trichloride, $\mathrm{BCl}_{3}$, and hydrogen, $\mathrm{H}_{2}$, in a plasma. The gases injected into RF plasma where they combined and formed boron powder via gas phase nucleation. Methane gas, $\mathrm{CH}_{4}$, was added in the case of carbondoped powder. These powders were found to be suitable for the fabrication of high performance superconducting magnesium diboride $\left(\mathrm{MgB}_{2}\right)$ wires. Plasma synthesized boron particles typically had the shape of low aspect ratio spheroids that tended to form open, lacy agglomerates. Particle sizes ranged from 10 to $250 \mathrm{~nm}$. A typical batch of boron powder contained a mixture of amorphous and crystalline material. In this study, the effects of plasma power and carbon dopant addition on the crystallinity, particle size, and microstructure of boron nanopowder were investigated using powder xray diffraction (XRD), scanning electron microscopy (SEM), transmission electron microscopy (TEM), and selected area electron diffraction (SAD). Particle size distribution was measured using SEM and TEM images. SAD patterns showed the characteristic halo of an amorphous material, but single crystal reflections were observed as well.

A powder-in-tube (PIT) method was used for the fabrication of $\mathrm{MgB}_{2}$ wire. The boron powder was mixed with $\mathrm{Mg}$ powder, and the combined powders were formed into wire in a continuous tube filling and forming (CTFF) process [8]. To make multi-filament wire, several monofilament tubes were stacked in a $\mathrm{Cu}_{0.7} \mathrm{Ni}_{0.3}$ can and the entire assembly was drawn to final size. The wires were subsequently heat treated at $650-700^{\circ} \mathrm{C}$ to fully react the $\mathrm{Mg}$ and $\mathrm{B}$. Critical current densities were measured by hysteresis [6] and transport methods [10] as previously reported.

\section{Analysis of powder}

Typical scanning electron micrographs of boron powders are shown in Figure 2. It was observed that powders synthesized at higher plasma powers had larger particle sizes. A transmission electron 
microscope (TEM) study of dozens of the powders showed a remarkable similarity among all the powders with regard to the range of particle sizes and the way the particles agglomerate into a very open structure similar to a three dimensional lace. Examples of particle size distributions are shown in Figures 3 and 4 . If low RF power in the neighborhood of $17 \mathrm{~kW}$ was used, the particle sizes ranged from 10 to $60 \mathrm{~nm}$. When the power was increased to 24 to $27 \mathrm{~kW}$, the particle sizes increased ranging from 20 to $250 \mathrm{~nm}$. A selected area diffraction picture of about 1000 to 2000 particles showed both the characteristic halo of amorphous material and diffraction spots from crystalline material, as shown by Figures 3 and 4 . High resolution TEM micrographs showed both amorphous and crystalline particles. Generally, small particles tended to be amorphous and the larger particles often showed crystalline regions (see Figure 4). The edges of the particles were usually amorphous and crystalline regions often developed in the interior of the larger particles. An x-ray diffraction study of different powders, shown in Figure 5 , indicates that there were $\beta$ - rhombohedral peaks in all the powders, but those synthesized using lower RF power had a lower peak-to-background ratio than those made with higher RF power. Normally, amorphous material exhibits a broad envelope of intensity in areas where corresponding crystalline material shows several well-defined, sharp peaks. In the case of the boron nanopowder synthesized for this study, diffraction peaks were observed that corresponded with crystalline $\beta$ rhombohedral boron, but the peaks were much more poorly defined and less resolved against a higher background, indicating a mixture of crystalline and amorphous material. It should be noted that the fullscale intensities displayed on the $y$-axis of Figure 5 differ significantly for each of the samples and are displayed for ease of examination. Because amorphous material diffracts weakly, it is difficult to accurately estimate the ratio of amorphous to crystalline material. Semi-quantitative estimates indicate that the boron nanopowder had an amorphous-to-crystalline ratio in the approximate range of $4: 1$ to $6: 1$, with the powder made at lower power (Figure $5 \mathrm{~A}$ ) containing the highest fraction of amorphous material.
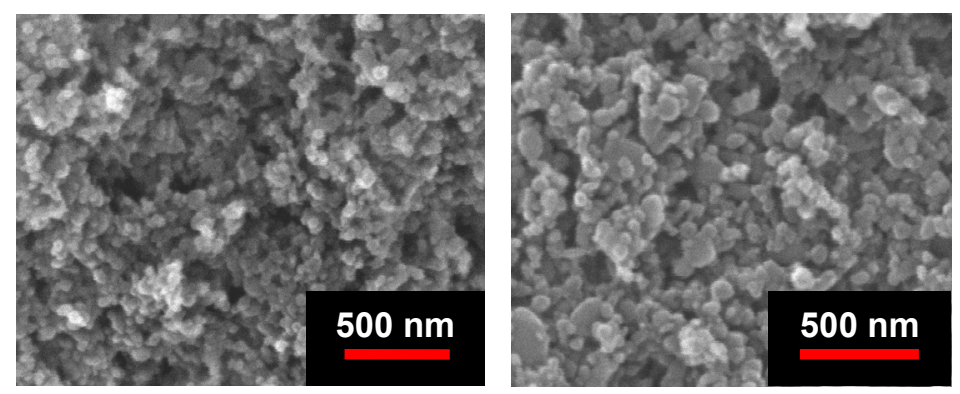

Figure 2. SEM micrographs showing boron powder made at two different plasma power levels. Lower power (left) resulted in particles ranging from 10-100 nm, while higher power resulted in larger particles (70- 

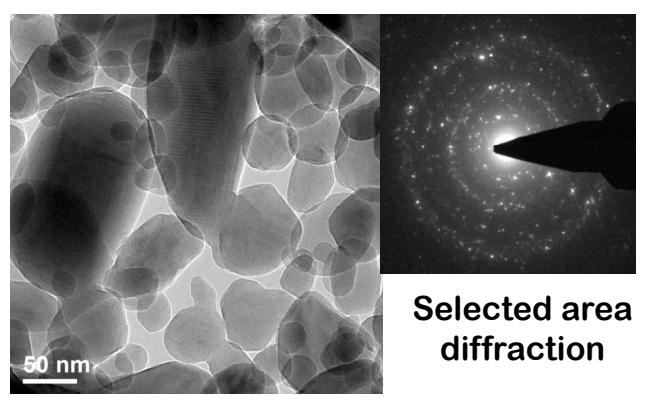

Selected area diffraction

TEM micrograph of powder

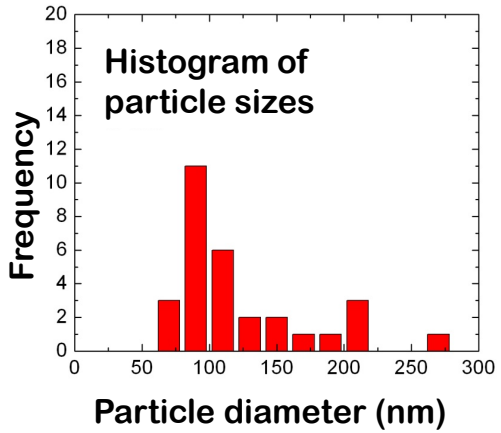

Particle diameter (nm)
Figure 3. Boron powder made at a higher plasma power ( $25 \mathrm{~kW})$ resulted in larger particles (70-250 $\mathrm{nm}$ ) than in powder made at lower power; SAD patterns showed a higher fraction of crystalline material than in powder made at lower power.

Figure 4. Boron powder (undoped \& doped) made at lower plasma power $(\sim 17 \mathrm{~kW})$ resulted in smaller particles (20$100 \mathrm{~nm})$. The powder was a mixture of amorphous and crystalline phases. The crystalline fraction was lower than seen in powder made at higher power. The HRTEM image (lower left) shows a mixture of crystalline and amorphous particles. 


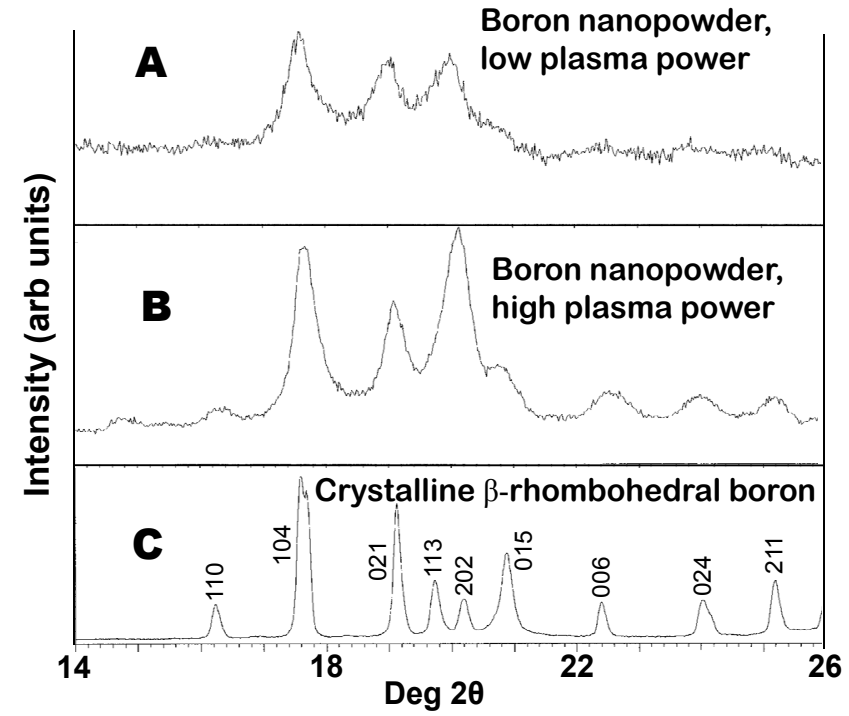

Figure 5. X-ray diffraction patterns of boron powder. Two samples of plasma synthesized boron (A\&B) nanopowder are shown and compared with that of fully crystalline $\beta$-rhombohedral boron (C, shown with $h k l$ Miller indices). The nanopowder is a mixture of crystalline and amorphous phases. The $x$-ray lines are progressively broadened from $C$ to $A$, consistent with powder $A$ (made at the lowest power) having the smallest crvstallite sizes and lowest fraction of

\section{Superconducting performance}

The superconducting transition temperatures, $T_{c}$, of wires made from these powders were determined by magnetization measurements. $T_{c}$ was found to decrease slowly and roughly linearly with increasing carbon content determined from the mixture of $\mathrm{CH}_{4}$ and $\mathrm{BCl}_{3}$ in the gas phase. Using the work of Wilke et al [11] for the $\mathrm{T}_{\mathrm{c}}$ vs \% carbon curve in carbon-doped $\mathrm{MgB}_{2}$, we find that the carbon-toboron ratio in the final $\mathrm{MgB}_{2}$ is about twice the carbon-to-boron ratio in the gas phase. For example, powders made with $2 \%$ carbon in the $\mathrm{CH}_{4}+\mathrm{BCl}_{3}$ gas phase contain $4 \%$ carbon in the superconducting $\mathrm{MgB}_{2}$ wire.

Critical current densities, $J_{c}$, have been determined from magnetic hysteresis loop measurements at both $5 \mathrm{~K}$ and $20 \mathrm{~K}$ as well as from wire transport measurements in a liquid helium bath at $4.2 \mathrm{~K}$. As shown in Figure 6, $\mathrm{J}_{\mathrm{c}}$ values run about $60,000 \mathrm{~A} / \mathrm{cm}^{2}$ at $5 \mathrm{~K}$ and $5 \mathrm{~T}$, and $25,000 \mathrm{~A} / \mathrm{cm}^{2}$ at $20 \mathrm{~K}$ and $3 \mathrm{~T}$ for a sample doped with about $4 \%$ carbon and reacted at $700^{\circ} \mathrm{C}$ for $20 \mathrm{~min}$. Typically, wires made with no carbon addition have a higher $\mathrm{J}_{\mathrm{c}}$ value than the $4 \%$ carbon samples at low magnetic field, and a lower $\mathrm{J}_{\mathrm{c}}$ value than $4 \%$ carbon samples at high fields, crossing over in the neighborhood of 2 to 3 Tesla for the $5 \mathrm{~K}$ data.

Important questions remain to be answered with regard to the preparation of these PIT wires. The wires consistently had a slightly lower $\mathrm{T}_{\mathrm{c}}$ than $\mathrm{MgB}_{2}$ made in pellet form from the same powder. In addition, when several different wires were made from the same powder, the value of $T_{c}$ often varied by about a degree Kelvin from sample to sample. Residual stress most likely plays some role in both the $T_{c}$ and $J_{c}$, and further optimization can yet be done with the wire drawing and reaction conditions. The plasma synthesis process is still in the development stage as well. More work needs to be done to investigate process conditions in order to produce boron powder with the optimal particle sizes, crystallinity, and dopant concentration for better $\mathrm{MgB}_{2}$ superconducting wires. 


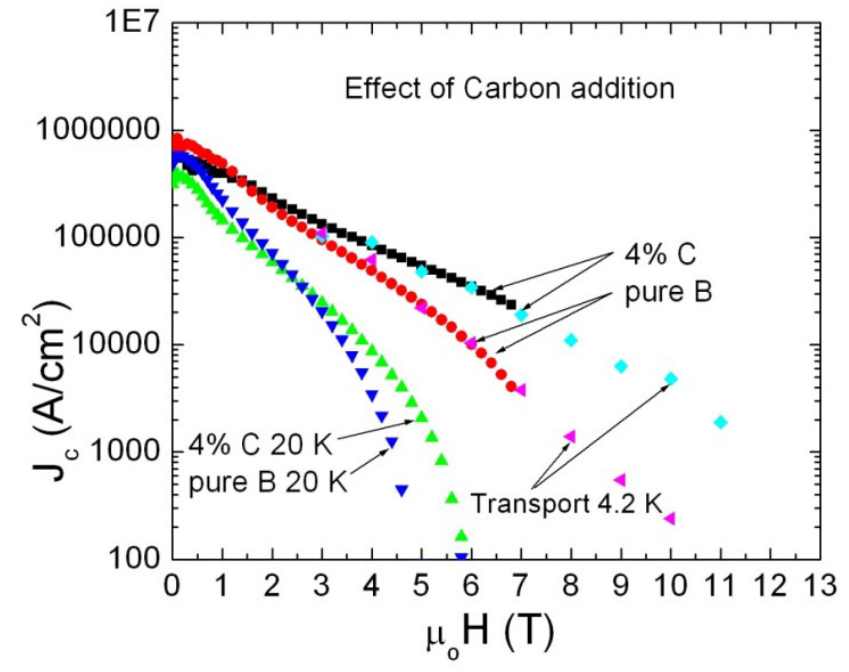

Figure 6. Comparison of critical current density for wires made with plasma synthesized boron nanopowders (undoped and $4 \%$ carbon doped); hysteresis data at $5 \& 20 \mathrm{~K}$ go to 7 Tesla. Transport data at $4.2 \mathrm{~K}$ go to 11 Tesla.

\section{Summary of initial powder studies}

Nano-sized boron powder was plasma synthesized under a range of process conditions, producing a mixture of amorphous and crystalline particles with sizes ranging from 10 to $250 \mathrm{~nm}$. The RF plasma power had a significant effect on the crystallinity and particle size of the powder. The addition of carbon dopant, while not appreciably affecting the size or crystallinity of the boron powder, favorably affected the critical current density of $\mathrm{MgB}_{2}$ superconductors at high magnetic fields. Plasma synthesis has been shown to be a viable process for producing doped boron powders for use in the fabrication of PIT superconducting $\mathrm{Mg}\left(\mathrm{B}_{1-\mathrm{x}} \mathrm{C}_{\mathrm{x}}\right)_{2}$ wires.

\section{Task 4: Nanopowder collection techniques}

\section{- Task Milestones}

- Study the effect of process pressure and flow on the efficiency of the installed cyclone powder collectors.

- Evaluate a prototype electrostatic precipitator for nanopowder collection.

\section{Task 4 Results}

Early in the program, it was found that cyclone collectors would not efficiently collect boron powder in the particle size ranges targeted in this program. Although there was not universal agreement among the several experts we consulted regarding cyclone collection technology, we experimentally determined that the cyclone collectors we originally had built for our powder system would not efficiently collect plasma synthesized boron nanopowder. Thus the cyclone collectors were removed and replaced with porous metal filters. This resulted in a dramatic improvement in collection efficiency from negligible powder collection when using cyclone collectors to $40-50 \%$ of theoretical yield when using porous metal filters. Filters with rated pore sizes of 5 micron and 0.3 micron both were found to collect powder at efficiencies so that batch sizes for long lengths of wire (100-1000 meters) 
could be fabricated. Figure 7 shows filter housings and a porous metal filter with boron nanopowder partially removed.

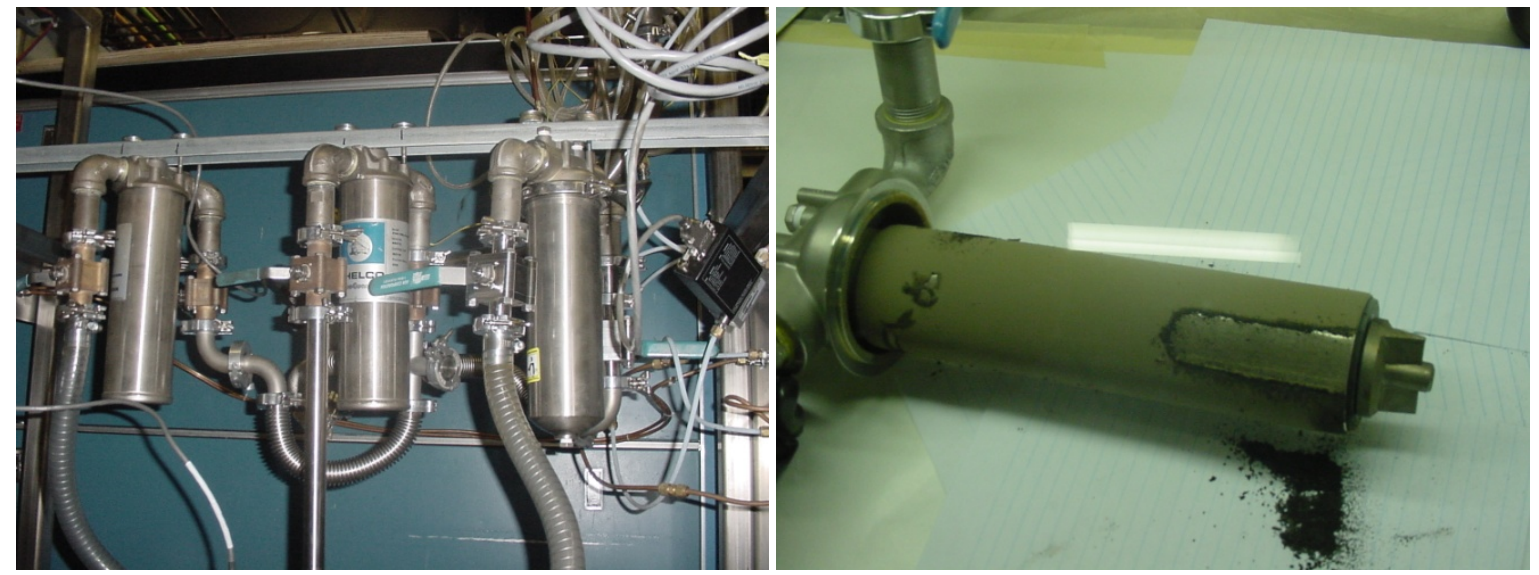

Figure 7. Housings for porous metal filters shown on the left. On the right, a porous metal filter with boron nanopowder is shown inside a nitrogen glove box.

The program continued to seek improvements in both the efficiency of the reaction in the plasma and the collection efficiency of the filters. Electrostatic precipitation was investigated and a design with a single stage cylindrical corona was assessed. The experts that were consulted both in academia and industry expressed skepticism due to three principal reasons: (1) the very small size and low atomic weight of boron; (2) the presence of a high concentration of hydrogen gas in the powder exhaust stream; and (3) the presence of corrosive hydrogen chloride byproduct gas in the powder exhaust stream. Thus, electrostatic precipitation was not further investigated.

Two alternate methods to improve powder collection and make the collection process more amenable to a scaled up continuous process. The first method was a blowback method in wish the collection filters were pressurized in order to force the powder away from the filter element and into another container so that collection could continue in a quasi-continuous fashion. Although partially successful, the static charge on the surface of the boron powder resulted in a low efficiency of pressureinduced removal from the filter cartridge. In addition, gas pressure tended to channel through the powder mass, resulting in removal of the powder in localized areas rather than homogeneous removal from the whole filter cartridge. The method that resulted was most successful in scaling up the powder collection was to gang several filter housings together as a unit. For example four cartridges were ganged together and when filled up, were valved off and removed from the system while simultaneously continuing collection in a second gang of four filters. This method of collection represents a hybrid of a batch process and a continuous process. By increasing the number of collection filters, the size of a batch increased from 20 grams at program beginning to over 200 grams by program end. The batch sizes could easily be scaled up at such at time when larger batches of powder are needed. 


\section{Task 5: Evaluation of Superconducting Properties}

- Task Milestones

- Measure superconducting properties on $\mathrm{MgB}_{2}$ made by reacting $\mathrm{B}$ nanopowder with $\mathrm{Mg}$ vapor as a way to choose the best combination of dopant chemistry and concentration for further development. This will be carried out on at least ten (10) different combinations of dopant conditions (dopant chemicals and concentrations).

- Perform $T_{c}, J_{c}, H_{c 2}$ (up to $16 T$ ) on all program material

- Perform $\mathrm{H}_{\mathrm{c} 2}$ evaluation at high fields using the facility at the National Magnet Laboratory using $\mathrm{MgB}_{2}$ made from boron nanopowders on at least two different combinations of dopant conditions (dopant chemicals and concentrations)

- Carry out all of above measurements on all PIT superconducting wire produced in this program

\section{Task 6: Fabrication of PIT Wire and Evaluation of Superconducting Properties}

Task Milestones

- Deliver at least twenty (20) lots of PIT wire (10-100m batches) with at least ten (10) different combinations of dopant conditions (dopant chemicals and concentrations) for use in Tasks 5

- Perform process optimization in preparation of commercial development on at least 3 different combinations of dopant conditions (dopant chemicals and concentrations)

- Synthesize 2-3 lots of 100-1000 meters of PIT wire on at least two different combinations of dopant conditions (dopant chemicals and concentrations) for incorporation in a prototype coil or other device

\section{Task 5 and 6 Results}

\section{Further analysis of $\mathrm{MgB}_{2}$ wires made from nano-sized boron powder}

Studies of the changes in $\mathrm{J}_{\mathrm{C}}(\mathrm{H}, \mathrm{T})$ are illustrated in Figure 8 for two batches of undoped boron powder, one from the plasma synthesis process described herein and the other from the decomposition of diborane. The magnetic field at which $J_{c}$ values cross $100,000 \mathrm{~A} / \mathrm{cm}^{2}$ line at $5 \mathrm{~K}$ is $5 \mathrm{~T}$, at $10 \mathrm{~K}$ is $4.3 \mathrm{~T}$, at $15 \mathrm{~K}$ is $3.5 \mathrm{~T}$, and at $20 \mathrm{~K}$ is $2.5 \mathrm{~T}$. For this particular plasma synthesized boron powder, the wire was reacted in a hot isostatic press at $30 \mathrm{ksi}$ and $950^{\circ} \mathrm{C}$ for 30 minutes to give a final density close to $90 \%$. The transport data at $4.2 \mathrm{~K}$ (solid triangles) are rather close to the $5 \mathrm{~K}$ hysteresis data (solid squares) even though the hysteresis currents are flowing circumferentially and the transport currents are flowing axially. Many other wires showed close correlations between hysteresis and transport measurements.

A more detailed comparison of our plasma synthesized boron powder with diborane boron is shown in Figure 9. The SB99 boron obtained from decomposing diborane is generally recognized to be very high quality amorphous boron powder, but is no longer available as a manufactured product. 


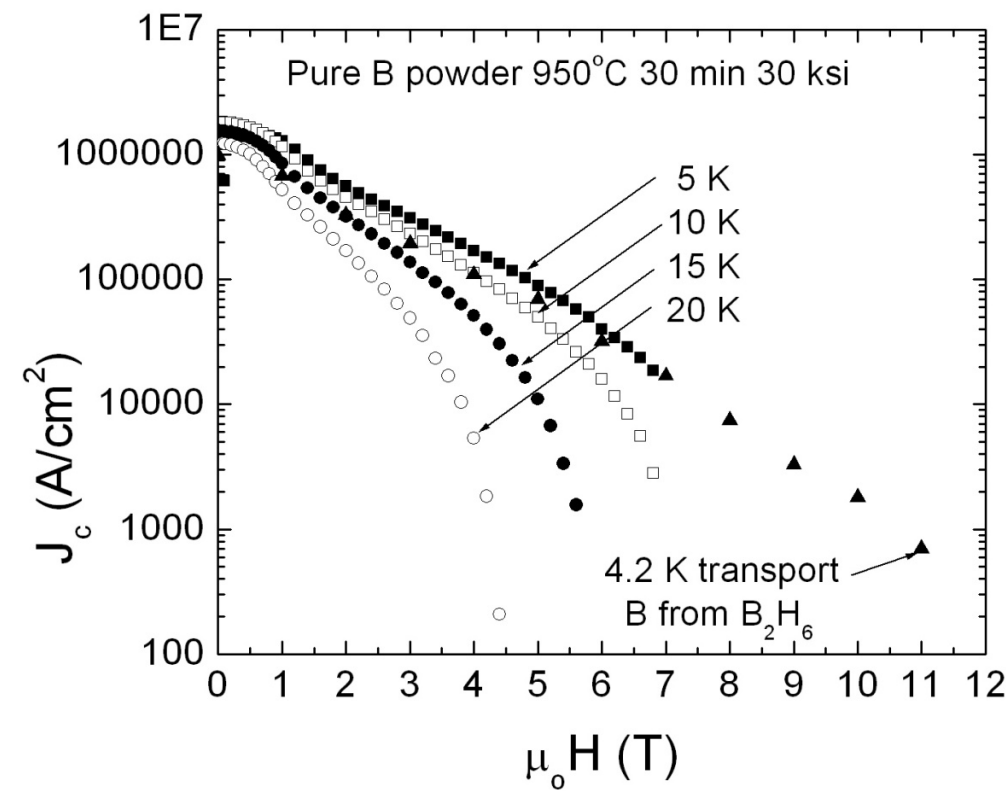

Figure 8. Temperature and magnetic field dependence of critical current density, $\mathrm{J}_{\mathrm{c}}$, for a wire reacted by hot isostatic pressing to a density of about $90 \%$ for the $\mathrm{MgB}_{2}$ core. For comparison, transport data are shown for an 18 filament wire made with boron powder

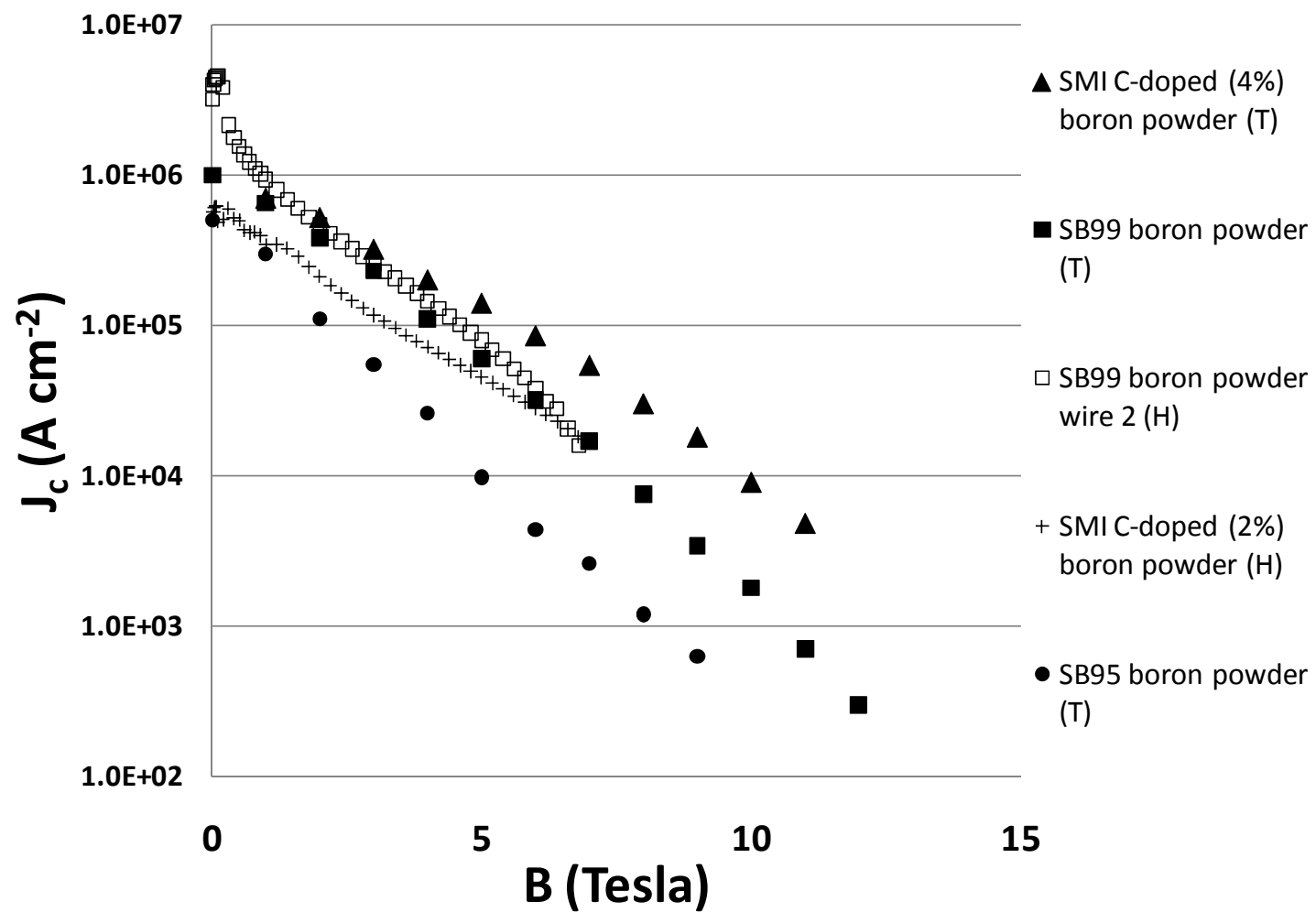

FIGURE 9. A comparison of wires made with several different batches of Specialty Materials powder with wires made with diborane derived boron, SB95 \& SB99 (undoped powder, nominally 95\% and 99\% pure respectively). The " $\mathrm{T}$ " denotes transport measurements at $4.2 \mathrm{~K}$ and the " $\mathrm{H}$ " denotes hysteresis measurements at $5 \mathrm{~K}$. 
Even if someone were to once again produce the equivalent of SB99 commercially, diborane is very expensive, pyrophoric, and extremely hazardous to handle in large quantities, which would preclude its use as a raw material for many $\mathrm{MgB}_{2}$ superconductor applications. The plasma synthesis process for boron powder was developed to produce high quality material that can perform comparably to powder made from diborane. RF plasma synthesis of boron is an electrodeless process [6] with the potential of producing higher purity material than a DC arc process in which electrode contamination can be problematic. Work reported by others [7] has shown that the quality of the boron precursor influences $\mathrm{MgB}_{2}$ superconducting properties. Figure 8 indicates the boron powder made in this study can be used to make $\mathrm{MgB}_{2}$ wire with performance characteristics that equal or exceed those made with SB99 [4]. The curve of $\mathrm{J}_{\mathrm{c}}$ performance $\mathrm{MgB}_{2}$ wire made with $\mathrm{SMI} 4 \%$ carbon-doped boron indicates that the wire maintains a current density of $>10^{5} \mathrm{~A} \mathrm{~cm}^{-2}$ up to magnetic field strengths of approximately 6 tesla.

Important questions remain regarding the preparation of these PIT wires. The wires consistently had a lower critical temperature, $\mathrm{T}_{c}$, than $\mathrm{MgB}_{2}$ made in pellet form from the same powder. Several wire fabrication parameters such as drawing conditions and the times and temperatures of the heating cycles need to be optimized in order to maximize the superconducting performance. Properties such as upper critical field, $\mathrm{H}_{\mathrm{c} 2}$, can significantly depend on the wire processing temperature (Figure 10). The plasma synthesis process needs to be further investigated with the goal of producing boron powder with the optimal particle sizes, crystallinity, and dopant concentration for better $\mathrm{MgB}_{2}$ superconducting wires. It should be pointed out that the powder mixing method used to make the C-doped wire shown in Figure 7 was different than that used for the C-doped wire shown in Figure 9, and resulted in different transport $J_{c}$ data. Figure 11 shows a more detailed study of the effect of carbon doping on the critical

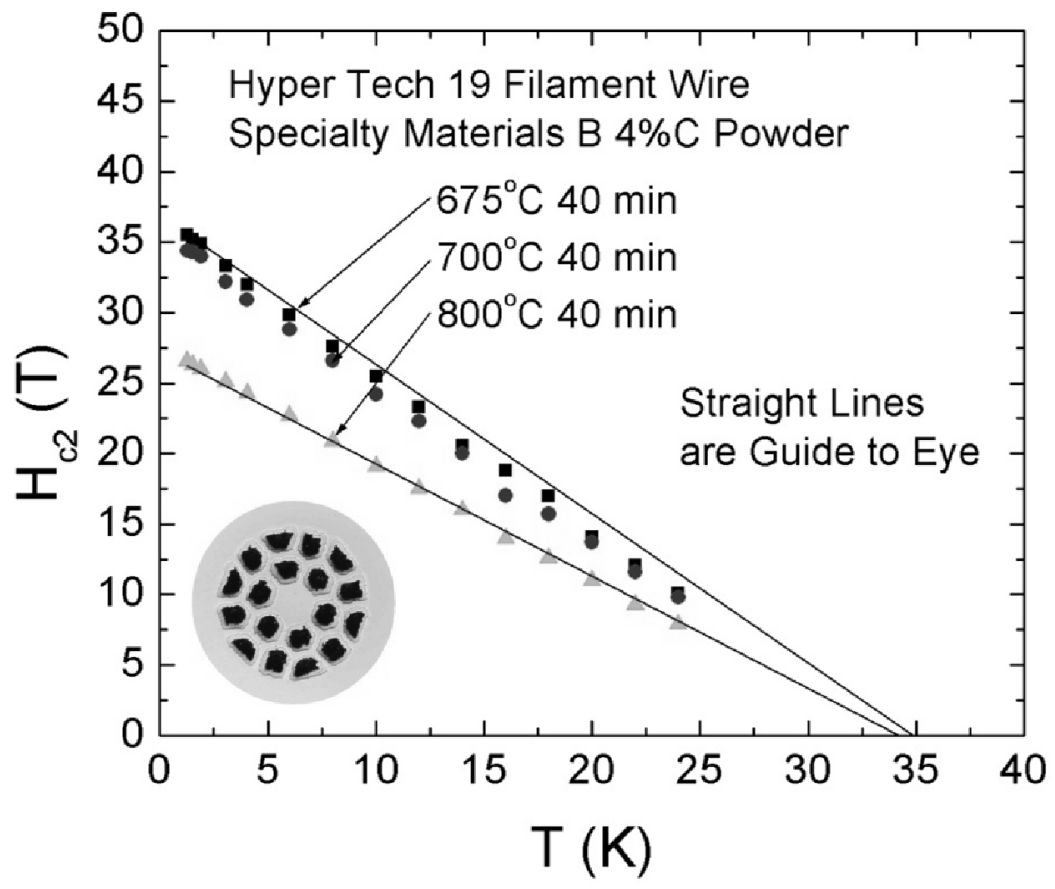

Figure 10. Upper

critical magnetic field data for 19-filament PIT wire samples (inset shows $\sim 2 \mathrm{~mm}$ diameter cross section) prepared from C-doped boron powder; the sample processed at $675^{\circ} \mathrm{C}$ shows $\mathrm{H}_{\mathrm{c} 2}(\mathrm{~T}=0) \sim 37 \mathrm{~T}$ 
current density. The wire fabrication method had been further improved relative to wires used in Figures 7-9. The best results were achieved at a carbon doping level of $3 \%$ and a wire fabrication temperature of $700^{\circ} \mathrm{C}$, showing a critical current density, $J_{c}$, of $10^{5} \mathrm{~A} \mathrm{~cm}^{-2}$ at 7-8 tesla. This far exceeds the proposed program goal of $10^{5} \mathrm{~A} \mathrm{~cm}^{-2}$ at 4 tesla.

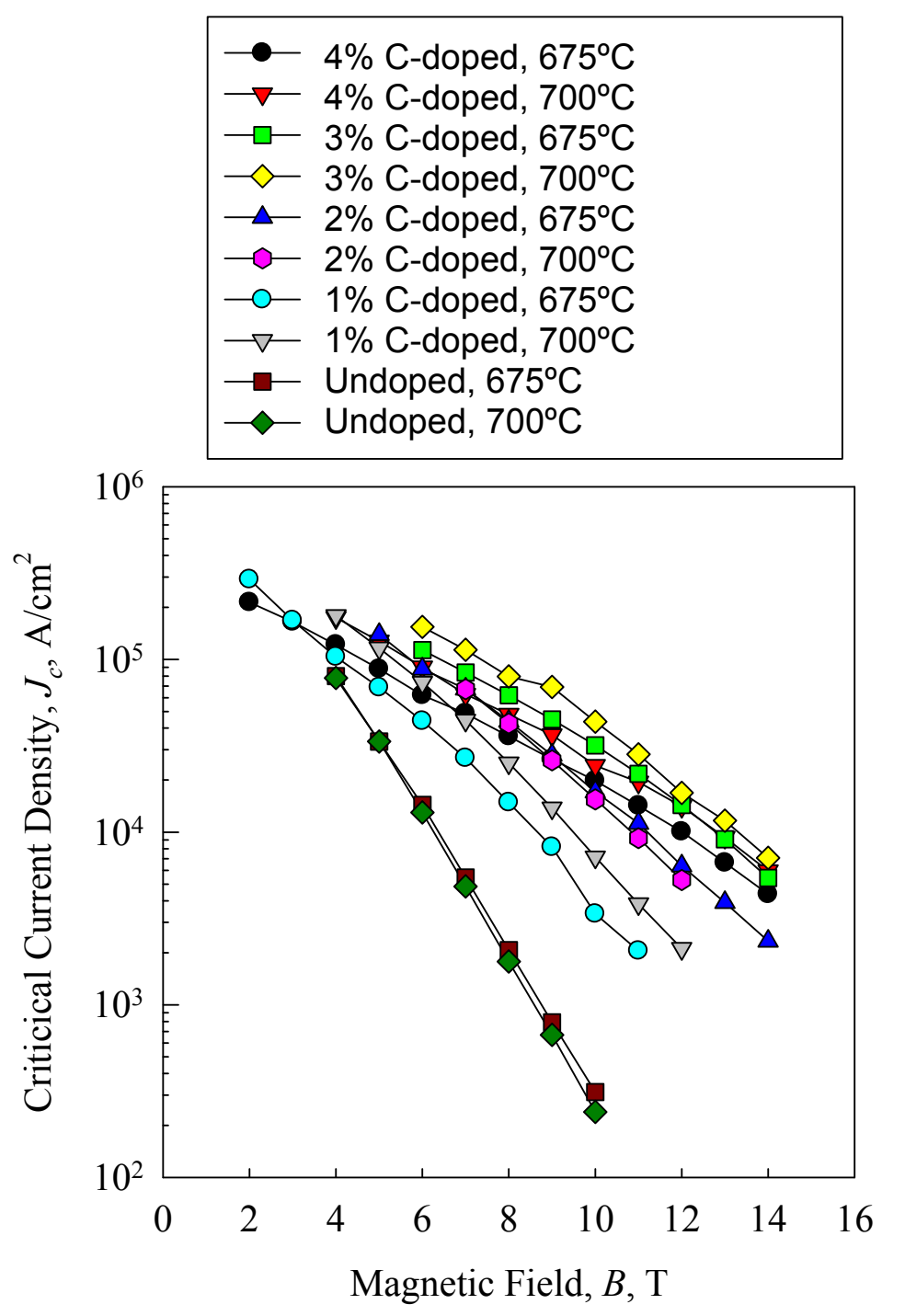

Figure 11. $\mathrm{MgB}_{2}$ superconductor wire results as a function of carbon doping levels and wire fabrication temperature. The best results were achieved at a carbon doping level of $3 \%$ and a wire fabrication temperature of $700^{\circ} \mathrm{C}$, showing a critical current density, $J_{c}$, of 100,000 $\mathrm{A} \mathrm{cm}^{-2}$ at 7-8 tesla. 


\section{$\underline{M g B}_{2}$ powder from boron nano-sized powder}

In an effort to find a satisfactory process for converting plasma synthesized boron into $\mathrm{MgB}_{2}$ powder, a series of experimental runs were made in which the nano-sized boron powder was placed in the bottom of a cylindrical Ta tube with a Ta cup holding the liquid Mg above it. These were then sealed in quartz and reacted in a box furnace for different times and temperatures. Figure 11 shows a scanning electron micrograph (SEM) of $\mathrm{MgB}_{2}$ powder made by the method described. The SEM micrograph shows that most of the powder consists of nano-sized particles $(<1000 \mathrm{~nm})$. The right-hand side of Fig. 11 shows particle size distribution obtained by the analysis of transmission electron (TEM) micrographs, indicating that most of the particles are less than $500 \mathrm{~nm}$.
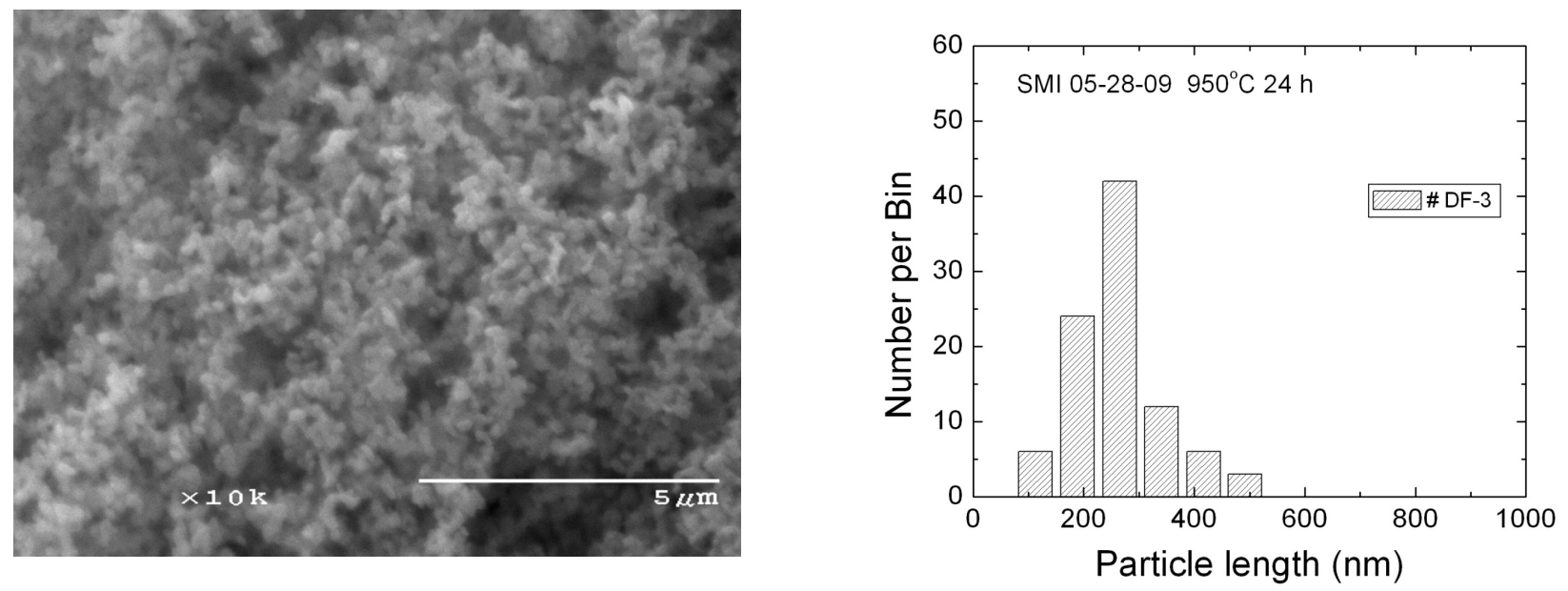

Figure 11. Scanning electron micrograph of $\mathrm{MgB}_{2}$ powder; the histogram on the right indicates that most of the particles are less than $500 \mathrm{~nm}$ in size.

Experiments to scale-up of the powder synthesis process continued throughout the program. Figure 12 is an high magnification SEM micrograph of powder made at a $400 \%$ higher rate than at the program start. There was no apparent decrease in the quality of the powder and the size range (10-200 $\mathrm{nm}$ ) was maintained relative to lower synthesis rates. 


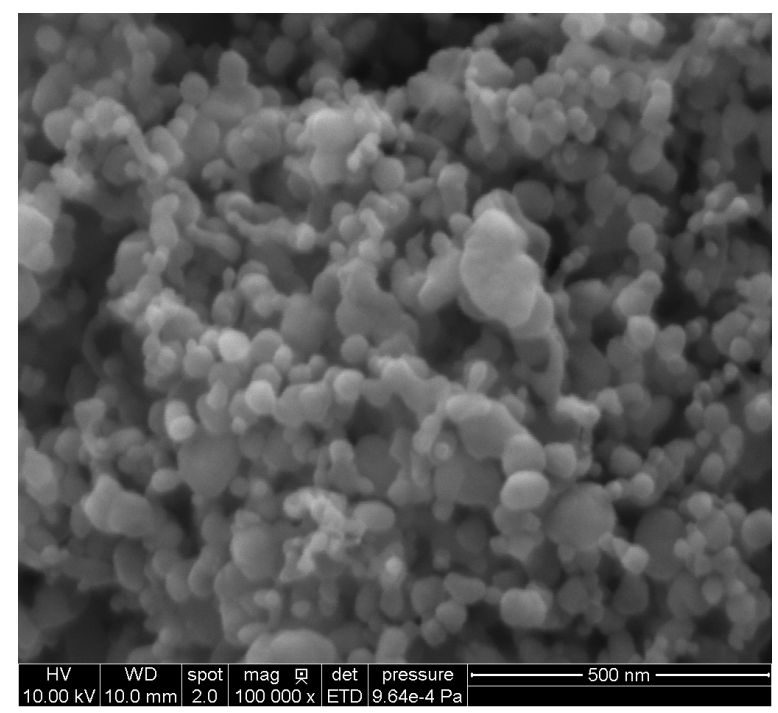

Figure 12. Carbon-doped boron powder made at a higher synthesis rate $(400 \%$ higher than at program start). There was no loss of powder quality and the size range of $20-200$ $\mathrm{nm}$ was maintained

\section{Task 7: Path to Commercialization}

- Task Milestones

- Cost-benefit analysis of manufacturing costs of project materials vs competition materials

- Determine the cost of developing applications for three potential markets

$\circ \quad$ Build a prototype for at least one potential market

\section{Task 7 Results}

Throughout the course of this program, Specialty Materials, Inc. worked closely with its collaborator Hyper Tech Research, Inc., who is making $\mathrm{MgB}_{2}$ wires for MRI magnets, fault current limiters, and several other applications. In addition to Hyper Tech, Specialty Materials has worked with several superconducting wire and magnet manufacturers including Siemens, Bruker, Columbus Superconductors. In answer to requests around the world, we have sent samples of ur nano-sized boron powder to companies and academic institutions in Europe, Asia, and Australian as well as the U.S. Hyper Tech Research has fabricated several kilometer lengths of $\mathrm{MgB}_{2}$ wire from our boron nanopowder. A prototype MRI coil is planned within two years.

In response to the MRI magnet industry, Specialty Materials has projected the cost of boron powder based on the annual rate of powder production (see Table 2). 
Table 2. Boron Powder Price Projection based on Annual Production Rate

$\begin{aligned} & \text { Specialty Materials, Inc. Nano-sized Boron Powder Price Estimates } \\
& \text { Price vs Annual Production Rate }\end{aligned}$
\begin{tabular}{|l|r|r|r|r|r|rc|r|r|r|r|r|}
\hline Production rate $(\mathrm{lb} / \mathrm{yr})$ & 30 & 100 & 300 & 800 & 3,500 & 25,000 & 50,000 & 100,000 & 130,000 \\
\hline Price $(\$ / \mathrm{lb})$ & $\$ 2,000$ & $\$ 1,400$ & $\$ 1,000$ & $\$ 800$ & $\$ 600$ & $\$ 500$ & $\$ 400$ & $\$ 350$ & $\$ 300$ \\
\hline
\end{tabular}

\section{Publications/Presentations Resulting from this Program:}

- Marzik, J.V., Lewis, R.C., Tillman, M.E., Wu, Y.Q., Finnemore, D.K., Rindfleisch, M., Tomsic, M., Yue, J., Croft, W.J., "Plasma Synthesized Boron Nano-sized Powder: The Effect of Processing Conditions on the Crystallographic and Microstructural Properties" Mater. Res. Soc. Symp. Proc. 1148-PP12-01, Materials Research Society, Warrendale, Pennsylvania, 2009. (presented at the Fall 2008 Conference of the Materials Research Society)

- J. V. Marzik, R. C. Lewis, M. R. Nickles, D. K. Finnemore, J. Yue, M. Tomsic, M. Rindfleisch, M. D. Sumption, "Plasma synthesized boron nano-sized powder for $\mathrm{MgB}_{2}$ wires", Advances in Cryogenic Engineering: Transactions of the Cryogenic Engineering Materials Conference-ICMC, 56, 295, (2010); also presented at the International Cryogenic Materials Conference, Tucson, Arizona, 2009.

- J.V. Marzik, D.K. Finnemore, W.K. Wu, M. Rindfleisch, M.A. Susner, M.D. Sumption, "Boron nano-sized powder synthesized in a plasma as a precursor for $\mathrm{MgB}_{2}$ powder and wires", submitted to the Applied Superconductivity Conference, Washington DC, August 2010

- M.A. Susner, M.D. Sumption, S.D. Bohnenstiel, Y. Yang, C.J. Kovacs, M.L. Border, E.W. Collings, M.A. Rindfleisch, M.J. Tomsic, and J.V. Marzik, "Efficiency of C-doping $\mathrm{MgB}_{2}$ via different routes", submitted to the Applied Superconductivity Conference, Washington DC, August 2010

- M.A. Susner, Y. Yang, M.D. Sumption, E.W. Collings, M.A. Rindfleisch, M.J. Tomsic, and J.V. Marzik, "Enhanced critical fields and superconducting properties of pre-doped B powder-type $\mathrm{MgB}_{2}$ strands", submitted to Supercond. Sci. Technol. 2010 


\section{References:}

1. J.V. Marzik, R.J. Suplinskas, R.H.T. Wilke, P.C. Canfield, D.K. Finnemore, M. Rindfleisch, J. Margolies, and S.T. Hannahs, "Plasma synthesized doped B powders for $\mathrm{MgB}_{2}$ superconductors", Physica C 423, 83 (2005).

2. L.D. Cooley, A.J. Zambano, and A.R. Moodenbaugh, "Carbon Inhomogeneity and Superconducting Properties of $\operatorname{Mg}(B, C)_{2}$ ", presented at the Meeting of the American Physical Society, Symposium G38, Baltimore, MD, March, 2006.

3. M.J. Tomsic, "Method for manufacturing $\mathrm{MgB}_{2}$ intermetallic superconductor wires", U.S. Patent 6,687,975 B2 (2004).

4. Sumption, M.D., Bhatia, M., Rindfleisch, M., Tomsic, M., and Collings, E.W. Supercond. Sci. and Technol. 19, pp. 1550160 (2006).

5. R.H.T. Wilke, S.L. Bud'ko, P.C. Canfield, D.K. Finnemore, R.J. Suplinskas, and S.T. Hannahs, "Systematic effects of carbon doping on the superconducting properties of $\mathrm{Mg}\left(\mathrm{B}_{1-\mathrm{x}} \mathrm{C}_{\mathrm{x}}\right)_{2}$ ", Phys. Rev. Lett. 92, 217003 (2004).

6. Hamblyn S.M.L., Reuben B.B., and Thompson R., "Hydrogen reduction of boron trichloride to boron in an R.F. plasma", in "Special Ceramics 5: Proceedings of the Fifth Symposium on Special Ceramics held by the British Ceramic Research Association at Queens Road, Penkhull, Stoke on Trent on July 14, 15 and 16, 1970", British Ceramic Research Association, Stoke on Trent, 1972, pp. 147-155.

7. Chen, S.K., Yates, K.A., Blamire, M.G., and Driscoll, J.L. Supercond. Sci. and Technol. 18, 1473 (2005). 